This item was submitted to Loughborough's Research Repository by the author.

Items in Figshare are protected by copyright, with all rights reserved, unless otherwise indicated.

\title{
Methods for quantifying the stable sintering region in laser sintered polyamide-12
}

PLEASE CITE THE PUBLISHED VERSION

http://dx.doi.org/10.1002/pen.23386

\section{PUBLISHER}

Wiley / @ Society of Plastics Engineers

VERSION

AM (Accepted Manuscript)

\section{PUBLISHER STATEMENT}

This work is made available according to the conditions of the Creative Commons Attribution-NonCommercialNoDerivatives 4.0 International (CC BY-NC-ND 4.0) licence. Full details of this licence are available at: https://creativecommons.org/licenses/by-nc-nd/4.0/

\section{LICENCE}

CC BY-NC-ND 4.0

\section{REPOSITORY RECORD}

Vasquez, Mike, Barry Haworth, and Neil Hopkinson. 2015. "Methods for Quantifying the Stable Sintering Region in Laser Sintered Polyamide-12". figshare. https://hdl.handle.net/2134/17438. 


\title{
Methods for Quantifying the Stable Sintering Region in Laser Sintered Polyamide-12
}

\author{
By M.Vasquez ${ }^{1}$, B. Haworth ${ }^{2}$, N. Hopkinson ${ }^{3}$ \\ ${ }^{1}$ Additive Manufacturing Research Group \\ Loughborough University, Loughborough, Leicestershire LE11 3TU, UK \\ ${ }^{2}$ Department of Materials \\ Loughborough University, Loughborough, Leicestershire LE11 3TU, UK \\ ${ }^{3}$ Department of Mechanical Engineering, The University of Sheffield, S10 2TN UK
}




\begin{abstract}
Manufacturing complex parts by the laser sintering process requires a minimum amount of energy input for consolidation of polymer particles to occur, however too much energy can result in a decline in mechanical properties. This decrease is thought to be the result of polymer chain degradation. A Stable Sintering Region (SSR) has been proposed to describe the optimum temperature range for successful laser sintering. This paper will aim to quantify the SSR for polyamide-12 by using thermogravimetric analysis (TGA) to provide a framework for identifying key laser sintering processing parameters. Weight loss with respect to temperature is the main measurement output of the TGA procedure. However, the precise temperature and thermal history of a material is difficult to quantify during the laser sintering process; instead an energy input approach has been developed. A degradation energy was calculated from the TGA data and was used in conjunction with a laser sintering formula called Energy Melt Ratio (EMR) to prescribe build parameters for laser sintered parts. The mechanical properties of these parts illustrated the effect of degradation at various levels of energy input. Implications for this work include optimizing the material selection process for polymer laser sintering materials beyond polyamide- 12 .
\end{abstract}




\section{Introduction}

Laser sintering is an additive manufacturing technology that uses a laser to consolidate prototype and end-use 3-Dimensional computer aided design objects from powdered material.[1] Although metal and ceramic powders are frequently processed using laser sintering, the focus of this work will be on polymers, specifically nylon (polyamide)-12. Polyamide 12 is the most commonly used laser sintering polymer (currently around $95 \%$ of the total laser sintering polymer market) however the range of available polymer materials is fairly limited in comparison to competitive processes such as injection moulding.[2] One of the main advantages of laser sintering over traditional moulding techniques is geometric freedom in part design, which has allowed successful utilisation of the process in diverse applications including ducting for fighter aircraft, i-Phone cases, and even rideable snowboard binding prototypes

During laser sintering, the build process takes place in a nitrogen controlled chamber. The polymer is heated to an elevated temperature prior to the commencement of the build. The actual sintering takes place on a bed of powder which in the case of polyamide 12 , is heated to a temperature about $12^{\circ} \mathrm{C}$ below the crystalline 'peak' melt temperature. Polyamide 12 is a semi-crystalline polymer that has a wide super-cooling region; this has been shown to be a key factor for laser sintering processing.[3] A direct beam $\mathrm{CO}_{2}$ laser applies energy to the material to take it above the melting point and to consolidate the specified area. After a layer of powder is sintered another layer of material is deposited onto the build using a counter-rotating roller or a blade. Typically the laser absorbance for laser sintering processes exceeds $90 \%$. [4][5][6] The unsintered powder surrounding the consolidated cross-section serves as a partsupport structure. This allows complex shapes to be constructed without the need for moulds and tooling.[7] When the build is complete the part is cleaned by removing this loose powder.

Control of the thermal conditions inside the laser sintering machine is one of the fundamental requirements for creating parts with good mechanical properties, since this is controlled by the rheological properties of the polymers at low deformation rates, specifically the temperature dependence of viscosity.[8][9] The factors that the operator controls while running the machine include laser power, laser scan count, scan spacing, and part bed temperature. There has been previous work to quantitatively 
correlate laser sintering inputs, including the Andrew's number and also the Energy Melt Ratio (EMR).[10] EMR is the ratio of the applied energy density relative to the theoretical energy to melt a single layer of material.[10] It is currently the most comprehensive and practical method to compare laser sintering parameters:

$$
E M R=\frac{\frac{P \times V_{C}}{V_{s} \times V_{B} \times z}}{\left[C_{p}\left(T_{m}-T_{b}\right)+h_{f}\right] \times\left(\delta_{s}\right)\left(\delta_{d}\right)}
$$

Where $\mathrm{P}, \mathrm{V}_{\mathrm{c}}, \mathrm{V}_{\mathrm{s}}, \mathrm{V}_{\mathrm{B}}, \mathrm{z}, \mathrm{C}_{\mathrm{p}}, \mathrm{T}_{\mathrm{m}}, \mathrm{T}_{\mathrm{b}}, \mathrm{h}_{\mathrm{f}}, \delta_{\mathrm{s}}, \delta_{\mathrm{d}}$ are laser power, scan count, scan spacing, beam speed, layer thickness, specific heat capacity, melting temperature, powder bed temperature, enthalpy of melt, material density, and packing density (respectively).

The effect of increasing energy density on part mechanical properties was investigated by Caulfield et al. [11] This work showed that tensile strength, modulus, and elongation at break generally increase with more input energy. Ho [12] obtained similar results with laser sintered bisphenol-A polycarbonate (PC) and Majewski [13] showed the same pattern exists following High Speed Sintering. These studies suggest that higher energy promotes more complete consolidation of powders during manufacture. The link between sintering variables and component properties is the development of internal structure during thermal processing. Zarringhalam examined the microstructure of a laser sintered PA-12 part which showed un-melted cores within a spherulitic texture, an indication that insufficient energy was delivered to induce full melting.[14] However, an optimum energy density appears to be reached, after which mechanical properties decline due to polymer degradation. Vasquez established the term 'Stable Sintering Region' to characterize the thermal window for effective laser sintering prior to the onset of significant material degradation[15]. 
There have been several other studies that have investigated thermal phenomena during the laser sintering process. Childs [5] and Dong [4] created two-dimensional and three-dimensional finite element simulations of the laser sintering process, respectively. Online optical temperature monitoring has also been adapted by Chivel for the process on customized machines.[16] Williams modelled the effect of various machine parameters like laser power and scan spacing on the laser sintering process.[17] Wiria et al. modelled the heat transfer process during laser sintering for tissue engineering scaffolds.[18] Using optical thermography it was shown that temperatures in the central part of the incident laser could increase by as much as $20^{\circ} \mathrm{C}$ with the addition of $1 \mathrm{Watt}$ on the laser power setting.[18]

Most polymers do not have an exact point of degradation, which is induced by thermally-activated chemical reactions; however attempts have been made to assess the acceptable thermal processing regions for more established technologies such as injection moulding. Work by Colin et al. used a combination of temperature and molar mass data to create polymer processability windows.[19] Because factors other than temperature can account for degradation (process residence time and mechanical stress), including mechanisms such as hydrolysis and themo-oxidation, thermal stability is not easily defined and is also difficult to predict in a manufacturing environment. Previous work by Ghosh and Herrera has outlined the chemical reactions that occur during degradation for polymers such as polyamide.[20][21] However, these studies did not examine the exact chemical reactions occurring during the laser sintering process for polyamide-12; instead, the aim of this research was to develop a quantitative method to connect the material characterisation data for PA-12 from TGA and then to utilise it to prescribe an optimum window for sintering, before the onset of degradation affects mechanical properties.

Bates et al. outlined a method to use TGA to create a thermal model to predict temperature distributions at a weld interface during transmission welding.[22] The method predicted an upper limit for the energy delivered to the interface of the weld. A similar method was implemented in the present study, applied to the laser sintering process. 
The Kissinger Method for analyzing degradation kinetics using TGA was the primary means for translating raw TGA data into a measure of energy required for degradation.[23] The mathematical explanation behind the method is described in the following section. Dynamic TGA records the weight loss of a material as it is heated at a controlled rate through a defined temperature region. It is noted that TGA measurements only record degradation indirectly, as it pertains to weight loss, and therefore circumstances where volatile compounds are released.

An outline of the assumptions for the Kissinger method is described below and has been adapted from Pramoda et al.[24] The rate of reaction can be defined as the ratio of actual weight loss to the total weight loss corresponding to the degradation process. This ratio $(\alpha)$ is shown in Equation 2 where $M, M_{0}, M_{f}$ are the actual mass, initial mass, and final mass, respectively.

$$
\alpha=\frac{\left(M_{0}-M\right)}{M_{0}-M_{f}}
$$

Equation 3 is the basic rate equation used in kinetic studies (where $\mathrm{k}$ is the rate constant, $\mathrm{f}(\alpha)$ is the rate of conversion, and $\mathrm{d} \alpha / \mathrm{dt}$ is the rate of degradation), illustrating that $\mathrm{f}(\alpha)$ is proportional to the concentration of reaction material.

$$
\frac{d \alpha}{d t}=k f(\alpha)
$$

The Arrhenius expression (4) is then used to describe the temperature dependence of the rate constant. Generally for the Arrhenius equation, k can be considered as the number of collisions that result in a given reaction per second. The pre-exponential factor (A) represents the total number of collisions (leading to a reaction or not) per second and the term $\left(-\mathrm{E}_{\mathrm{a}} / \mathrm{RT}\right)$ is the probability that for any given collision, a reaction will occur where $\mathrm{E}_{\mathrm{a}}$ and $\mathrm{R}$ are the activation energy and gas constant, respectively. 


$$
k=A \exp \left(-\frac{E_{a}}{R T}\right)
$$

The TGA protocol measures weight loss using a constant heating rate of $\beta$ :

$$
\beta=\frac{d T}{d t} \rightarrow d t=\frac{d T}{\beta}
$$

Combining equations 1.2-1.5 results in equation 6 and simplifies to Equation 7:

$$
\begin{aligned}
& \beta \frac{d \alpha}{d T}=A f(\alpha) e^{-\frac{E_{a}}{R T}} \\
& \frac{d \alpha}{f(\alpha)}=\frac{A}{\beta} e^{-\frac{E_{A}}{R T}} d T
\end{aligned}
$$

Equation 1.8 can be integrated within the constraints of initial temperature $\left(\mathrm{T}_{\mathrm{o}}\right)$ corresponding to a degree of conversion $\left(\alpha_{o}\right)$ and a peak temperature $\left(T_{p}\right)$ corresponding to $\alpha_{p}$

$$
\begin{gathered}
\int_{T_{0}}^{T_{p}} e^{-\frac{E_{A}}{R T}} d T \\
\ln \left(\frac{\beta}{T_{\max }^{2}}\right)=-\frac{E_{A}}{R}\left(\frac{1}{T_{\max }}\right)+\ln \left(\frac{A R}{E_{A}}\right)
\end{gathered}
$$

The Kissinger method for solving equation 8 assumes that $\mathrm{n}=(1-\alpha)^{\mathrm{n}-1}=1$

$$
\begin{gathered}
\ln \left(\frac{\beta}{T_{\max }^{2}}\right)=\left[\ln \frac{A R}{E_{A}}+\ln \left(n\left(1-\alpha_{\max }\right)^{n-1}\right]-\frac{E}{R T_{\max }}\right. \\
\ln \left(\frac{\beta}{T_{\max }^{2}}\right)=-\frac{E_{A}}{R}\left(\frac{1}{T_{\max }}\right)+\ln \left(\frac{A R}{E_{A}}\right)
\end{gathered}
$$


Based on equation 11 one can solve for the activation energy $\left(\mathrm{E}_{\mathrm{A}}\right)$ by plotting $\ln \left(\beta / \mathrm{T}_{\max }{ }^{2}\right)$ as an ordinate, versus $1 / \mathrm{T}_{\max }$ at various heating rates. This results in a linear plot whose slope can be evaluated to determine the activation energy for degradation. Equation 11 was therefore applied to analyse the PA12 TGA data in the following sections of this paper.

\section{Methods}

Two thermal techniques were employed to characterize a virgin laser sintering grade of polyamide-12, PA 2200 supplied by EOS Gmbh (Munich, Germany) with an average particle size of $56 \mu \mathrm{m}$.[25] Standard differential scanning calorimetry (DSC) and thermogravimetric analysis techniques were used to outline the 'Stable Sintering Region' of the material. Further analysis using the Kissinger method was applied to the TGA results, as described in the previous section. The combination of DSC and TGA allowed for a complete analysis of the thermal response to a dynamic heating scan, from solid-state to melt-phase and finally to chemical breakdown.

DSC

Differential Scanning Calorimetry is a thermal measurement technique that tracks the heat flow to / from a sample during phase transitions, when subjected to a thermal scan. It is a common technique used for characterizing polymer laser sintering materials. A TA Instruments Q200 was used to perform the thermal analysis on the polyamide-12 powder sample. The ASTM D3418-08 protocol was followed for heating and sample preparation.[26] Two separate samples of mass $6.6 \pm 0.1 \mathrm{mg}$ from the virgin batch of material were heated from $20-220^{\circ} \mathrm{C}$ at $10^{\circ} \mathrm{C}-\mathrm{min}^{-1}$. Samples were sealed inside an aluminium container and nitrogen gas was used to create an inert atmosphere, circulated at a flow rate of $50 \mathrm{~cm}^{3} \mathrm{~min}^{-1}$. Results were analyzed using TA Universal Analysis Software.

TGA

Thermogravimetric Analysis is another common tool for assessing the thermal characteristics of a material. TGA is primarily used to investigate degradation in materials and can provide insight into 
volatility, moisture content, lifetime prediction, and to determine fillers or other inorganic media. An indium calibrated TA Instruments SDT 2960 was used to test powder samples heated from $30^{\circ} \mathrm{C}$ to $600^{\circ} \mathrm{C}$ in a $95 \%$ nitrogen atmosphere. The choice of atmosphere was made to simulate the conditions that are commonly used in laser sintering machines. Three separate tests were completed on samples of the virgin powder and data was analyzed using TA Universal Analysis software at heating rates of $5^{\circ} \mathrm{C}-\mathrm{min}^{-1}, 10^{\circ} \mathrm{C}$ $\min ^{-1}$, and $20^{\circ} \mathrm{C}-\min ^{-1}$.

\section{Hot Stage Microscopy}

Hot stage microscopy was used as a practical measurement of the coalescence of PA-12 powder particles to complement the predicted sintering onset position. A Leica light microscope with a dynamic heating rate program between $40^{\circ} \mathrm{C}-220^{\circ} \mathrm{C}$ at $10^{\circ} \mathrm{C}-\mathrm{min}^{-1}$ was used to observe the behaviour of a thin layer of polymer particles on a glass slide.

Gel Permeation Chromatography

In order to calculate the energy values required for thermally induced polymer chain degradation it was necessary to perform molecular weight measurements on the PA 2200 samples. This was completed at Smithers Rapra Technology Limited (Shawbury, UK) using conventional high temperature gel permeation chromatography. A single solution of the sample was prepared using $10 \mathrm{~mL}$ solvent $(1,1,1,3,3,3-$ hexafluoro-2-propanol) to $20 \mathrm{mg}$ of PA 2200 powder. The mixture was left overnight to dissolve and then was mixed and filtered through a $0.45 \mu \mathrm{m}$ PTFE membrane prior to chromatography.

\section{Laser Sintering Build}

The energy values calculated from the TGA data were converted to Energy Melt Ratio values that corresponded to the predicted energy required to impart degradation. The details of this procedure are outlined in the next section. An EOS P100 laser sintering machine was used to produce Type IV tensile specimens according to the ASTM Standard D638-10 Standard Test Method for tensile properties.[27] Figure 1 shows the build setup and the dimensions of the test pieces. There was a $6 \mathrm{~mm}$ layer before the first sintered layer and $3 \mathrm{~mm}$ after the final sintered layer. The tensile bars were built in the so-called YX 
direction on the build area, ie. on the horizontal plane of the bed, with the long dimension of the test piece in the Y-direction.

Laser power (between $6-25 \mathrm{~W}$ ) was chosen to be the primary variable between the test specimens. Sets of seven tensile bars were built at each power setting, five of which were used for testing. Table 1 shows the machine parameters used during the build.

\section{Tensile Testing}

Test specimens were conditioned at $20^{\circ} \mathrm{C}\left( \pm 1^{\circ} \mathrm{C}\right)$ and at 50 percent $( \pm 5 \%)$ relative humidity prior to testing. A Zwick Z030 tensometer fitted with a long travel contact extensometer was used to perform the tests. Modulus data were measured at $1 \mathrm{~mm} / \mathrm{min}$ crosshead speed to $0.25 \%$ strain, following which the tensile strength and elongation at break were measured at $5 \mathrm{~mm} / \mathrm{min}$ until specimen failure. The software provided by Zwick, TestXpert, was used to for the calculation of the tensile strength, Young's Modulus, and elongation at break for each of the parts.

\section{Results}

The laser sintering grade of PA12 has a crystalline melting point of $185^{\circ} \mathrm{C}$ and a melt enthalpy of $97.2 \mathrm{~J} / \mathrm{g}$. PA-12 is a semi-crystalline polymer and has relatively sharp melt and recrystallization peaks. The specific heat capacity of the material was $3250 \mathrm{~J}-\mathrm{kg}^{-1}-\mathrm{K}^{-1}$. Figure 2 illustrates a slight correction for the TGA data in order to account for the moisture content existing in the powder. Moisture content can be a concern for polymer powders especially for polyamides Throughton [28]. Because the physical moisture uptake of the polymer can occur quickly it was decided that for the TGA protocol the polymer would be tested as received and not pre-dried before testing. In order to correct for any excess moisture that the sample of powder may absorb during handling, the TGA results were adjusted to take this into account. The amount of weight loss that the sample showed from $0-100^{\circ} \mathrm{C}$ was subtracted from the total mass data and a secondary graph was created. The remaining graphs in the results section have been adjusted with the moisture content factor subtracted, so that further analysis of weight percent is independent of moisture content. On average the moisture content in the samples was in the range $0.2-0.3 \%$ for PA-12. Modified TGA data for the various heating rates tested are shown in Figures 3-4. 
The minimum onset temperature to allow polymer flow during laser sintering is towards the lower region of the graph (verified in practice using optical hot stage microscopy in Figure 5). This is a practical technique in which sintering kinetics can be observed and predicted sintering rates can be assessed using the Frenkel model. The upper temperature limit was selected in this instance from TGA, for $1 \%$ weight loss for a heating rate of $10^{\circ} \mathrm{C} \mathrm{min}^{-1}$. The stable sintering region resulting from the two analytical techniques (DSC; TGA) is shown in Figure 6.

\section{TGA Kissinger Method Calculation}

Thermal analysis data from TGA were analysed using the Kissinger Method, applied to PA12 at various heating rates. The key data points that were necessary to perform the calculation are highlighted in Figure 7. The temperature at which the maximum degradation occurred, identified by the derivative mass loss data, was identified for each of the heating rates. The $\mathrm{T}_{\max }$ values for the three heating rates are shown in Table 2. Figure 8 shows the resultant Kissinger plot for PA-12. The GPC molecular weight data are shown in Figure 9 and were used to convert the Kissinger result of $279.5 \mathrm{~kJ}^{-\mathrm{mol}^{-1}}$ to a value of $0.014 \mathrm{~kJ}^{-\mathrm{g}^{-1}}$.

Procedure to Determine Laser Sintering Parameters using EMR

The Energy Melt Ratio (EMR) (Starr et al) was used as a conduit between the Kissinger TGA data and the physical settings for the laser sintering machine. The following steps outline the procedure developed to predict machine settings that would induce degradation and quantify the upper limit of the stable sintering region.

EMR is obtained from practical energy density data, relative to the theoretical amount of thermal energy required to melt a given layer of polymer within the sintering process. The first step is to determine the energy density corresponding to degradation onset as determined by TGA (equation 12). Table 3 shows the values needed for the calculations where $T_{\text {DegOnset, }} E_{A}, M_{w}$ are the temperature for degradation onset, activation energy, and molecular weight, respectively.

$$
E_{\text {Deg }}=\left[\left(T_{\text {Degonest }}-T_{m}\right) C_{p}+E_{A} M_{w}\right]
$$


Therefore:

$$
E_{\text {Deg }}=0.43 \frac{\mathrm{J}}{\mathrm{mm}^{3}}
$$

Next, the energy required to melt a single layer of PA-12 powder was calculated according to the denominator of the Energy Melt Ratio equation. Table 4 includes the relevant variables that are necessary for equation 13 where $E_{m}$ is the energy required to melt a layer of material and $p$ is the packing density.

$$
\begin{gathered}
E_{m}=\left[C_{p}\left(T_{m}-T_{b}\right)+h_{f}\right] \times\left(\delta_{s}\right)(p) \\
\mathrm{E}_{\mathrm{m}}=0.069
\end{gathered}
$$

An energy melt ratio required for degradation is obtained by dividing equations [12] by [13].

$$
E M R_{D}=\frac{E_{D}}{E_{m}}=\frac{0.43}{0.069}=6.2
$$

The Energy Melt Ratio corresponding to degradation was 6.2. This predicted EMR was then used to determine the machine parameters (laser power, scan spacing, layer thickness, and beam speed) that would induce degradation in the material. The only variable that was changed for the laser sintering builds was laser power. The scan spacing, beam speed, layer thickness, and scan count were all kept constant and their values are shown in Table 5.

Calculate machine parameters at degradation EMR

$$
\left(E M R_{D}\right)\left(E_{m}\right)=\frac{P \times V_{c}}{V_{s} \times V_{b} \times z}
$$

Using this theoretical approach, the predicted laser power for degradation under these processing settings was 21 Watts. Therefore a set of tensile bars were constructed in the same build ranging from 6-25 Watts to explore possible effects of process induced material degradation. Figure 8 shows the visual effect of increasing the input energy for the build. The tensile specimens on the left appear lighter in colour, 
suggesting that just the top surface of particles are being melted. In contrast, the higher laser power specimens scatter more light (appear more 'glossy') suggesting a greater degree of melting, overall. Note that seven layers of parts were made in the build and the position of each part according to laser power was randomised to minimise any effects of position in the build bed on properties.

$$
(6.2)(0.069)=\frac{P \times 1}{(2500) \times(0.1) \times 0.20}
$$

Tensile properties data (Young's Modulus, Tensile Strength, and Elongation at Break) are plotted as a function of Energy Melt Ratio in Figures 9-11. Each of the figures identify the predicted point of degradation (6.2 EMR).

The initial positive relationships observed in the plots are induced by increased efficiency in the sintering process, as more thermal energy is transferred to the PA-12 powder; melt-state viscosity decreases with temperature (Haworth et al, 2011) once the EMR is sufficiently high to raise the typical sintering temperature above the crystalline melting endotherm. Similar qualitative trends are observed for all properties investigated (Figures 11-13); however modulus data show the highest level of variability, due to the non-linear behaviour of the PA12 materials.

As EMR increases, resulting in a progressive increase in powder sintering temperature, properties increase towards optimum levels, before detectable decreases are observed. Since this region corresponds to the EMR at the predicted degradation point, practical verification of the approach has been achieved.

\section{Discussion}

The tensile data have shown that there are plateaus and declines in the mechanical properties that are consistent with previous reported research. Furthermore, the peaks and onset of plateaus surround the predicted degradation Energy Melt Ratio proposed in this paper. The Young's modulus peaked at an EMR value less than predicted and stayed fairly constant however the property values were still roughly $15 \%$ below the maximum value. The peak stress was maximal at $53.9( \pm 1) \mathrm{MPa}$ at $18 \mathrm{~W}$ power, then decreased at both 22 and 25 Watts (a 3.5\% decrease in properties from the maximum value beyond the point of predicted degradation). There was a very clear peak in mechanical properties for the elongation at break 
parameter, the maximum occurred very close to the predicted EMR. Above 22W (6.38 EMR) however there was a about a 5\% decline in properties and this trend would have been expected to continue, at higher power input levels. These results confirm the existence of a 'stable sintering region' between the melting endotherm and the onset of material decomposition.

The estimated degradation point is based upon an assumption that a $1 \%$ weight loss is the critical point at which mechanical properties would be affected for polyamide-12 in laser sintering processes. This weight loss percent corresponded to the upper processing temperature range for injection moulding and was deemed as a reasonable estimation of the temperature region that would start to affect properties. However, based on the tensile data above, the critical EMR might be close to, but slightly higher: around 6.38 EMR (or 22 Watts power). Utilizing the method outlined in the previous sections an EMR value of 6.38 at these specific laser sintering parameters would suggest a measurable TGA weight loss between $1 \%-1.25 \%$. In commercial practice, it would be best most useful for users to maintain energy input values just below the critical point of degradation from input of the laser. The small discrepancy in degradation point could be due to several reasons including thermal inefficiency, such that the total amount of energy imparted by the laser is only partially absorbed by the polymer.

Laser sintering is a difficult process on which to predict exact outcomes, based on a complex set of independent but interactive variables and some inherent differences from machine to machine. However, one of the main benefits of the reported approach is that through a set of analytical tests on competitive materials (DSC, TGA, GPC), it is possible to specify a set of parameters that are close to the values of property maxima. This could be beneficial not only for future development of materials, but also to allow optimum process parameters to be specified more exactly based upon measured physio-chemical properties of the polymers. Laser sintering can be quite time consuming due to long warm up and cool down times and this can limit the amount of materials development that is possible on a single machine, thus restricting the commercial potential of the process to some extent. In the current study, it is also noted that PA12's large super cooling window enables a significant range of energy inputs to be tested, which might be difficult to recreate with materials that have a small super-cooling process windows that tend to curl or crash builds when large temperature differences are introduced between the sintered area and the fresh powder being applied for the next layer. 


\section{Conclusion}

This research has utilised DSC and TGA thermal characterisation methods to quantify the stable sintering region for PA-12, in terms of the 'Energy Melt Ratio' parameter defined elsewhere. It has been shown that data so-derived can be used in a theoretical approach using the Kissinger method, in conjunction with the energy melt ratio, to assess and define the upper limit for machine parameters for PA12. Practical data has verified that component mechanical properties reached maximum values within the stable sintering region, then decreased at higher energy input values corresponding to those determined theoretically. The predicted values of power / EMR required so that $1 \%$ degradation causes significant property deterioration were slightly high for tensile modulus but were much closer for elongation at break and peak stress, which showed roughly $5 \%$ and $3.5 \%$ decline in properties above this point, respectively.

A theoretical approach to define a stable region for laser sintering of polymers is therefore proposed. Ongoing work will aim to validate the concept with the same technique, using other laser sintering materials. Understanding the stable sintering region in a quantitative manner could help to expedite the selection process for new laser sintering materials. It is believed that materials with a broader process window (wider stable sintering region) would prove to be better candidates for development in laser sintering. This science-based methodology also offers improved process control and consistency, thereby reducing lead-time for maximizing part properties, such that the current 'trial and error' and experience-based methods can be eliminated, offering potential to save time and material whilst improving part consistency.

\section{References}

1. N. Hopkinson, R. Hague, and P. Dickens, (eds), Rapid Manufacturing and Industrial Revolution for the Digital Age, Chichester: John Wiley and Sons Ltd (2005).

2. T. Wohlers. Wohlers Report. Wohlers Associates, 250 (2009).

3. E. Dickens.; Lee, B.; Taylor, G.; Magistro, A.; Hendra, N.; McAlea, K.; Forderhase, P. United States Patent, 5,527,877 (1996). 
4. L. Dong; A. Makradi; S. Ahzi; Y. Remond. J. Matls Proc Tech, 209, 700-706 (2009).

5. T. Childs, C. Hauser, M.Taylor, A. Tontowi, Proc. Solid Freeform Symp-Austin, TX. 100-109, (2000)

6. A. Franco, M. Lanzetta, L. Romoli, J. Cleaner Production, 18, 1722-1730, (2010).

7. R.Goodridge, C. Tuck, R.Hague, 2011. Prog in Mat Sci. 57, (2011).

8. P. Hornsby, A. Maxwell, J. Mat. Sci., 27, 2525-2533 (1992).

9. B. Haworth,. Hopkinson, Hitt, D., Zhong, X. Rapid Proto. J., Accepted for Publication, (2012).

10. T. Starr, T. Gornet, J. Usher, C. Schwerzer, Solid Freeform Symposium, Austin, Texas (2009).

11. B. Caulfield, P. McHugh S. Lohfeld, J. Matls. Proc. Tech. 182 477-488 (2007).

12. H. Ho, W. Cheung, I. Gibson, I. Ind. Eng. Chem. Res. 42 1850-1862. (2003).

13. C. Majewski, B. Hobbs, N. Hopkinson. Virtual and Physical Prototyping, 2 pp. 103-110, (2007).

14. H. Zarringhalam, C. Majewski, N. Hopkinson, N., Rapid Proto. J, 15, (2009).

15. M. Vasquez, B. Haworth, N. Hopkinson, Proc. IMechE Part B: J. Eng. Manuf.. 225 (2011)

16. Y. Chivel, I. Smurov, Physics Procedia. 5, 515-521 (2010).

17. J. Williams, C. Deckard, C. Rapid Proto J. 4 90-100. (1998)

18. F. Wiria, K. Leong, C. Chua, Rapid Proto J. 16 400-410 (2010).

19. X. Colin, J. Verdu, CR Chimie 1380-1395 (2006).

20. S. Ghosh, D. Rastgir, A. Bhowmick, P. Mukinda. Polym Deg and Stab 67 427-436.(2000)

21. M. Herrera, G. Matushchuk, A. Kettrup Chemosphere 42 601-607, (2001).

22. P. Bates, S. Khosravi, G. Zak, ANTEC 20011-Proceedings of the $69^{\text {th }}$ Annual Technical Conference and Exhibition, Boston, 1855-1862, (2011).

23. H. Kissinger, Analytical Chemistry. 29. 1702-1706 (1957).

24. K. Pramoda, T. Chung, S. Liu, H. Oikawa. A. Yamaguchi,. Polym Deg Stab, 67 365-374, (2000).

25. EOS Data Sheet PA2200

26. American Society for Testing and Materials. D3418-08. ASTM International. (2008)

27. American Standards and Testing Methods. D638-10, (2010).

28. M. Troughton, Handbook of Plastics Joining: A Practical Guide. William Andrew Publishing (2008) 

Table 1 E0S P100 Build Settings

\begin{tabular}{ll}
\hline Parameter & Set point \\
\hline Layer Thickness & $0.1 \mathrm{~mm}$ \\
Part Bed Temperature & $172{ }^{\circ} \mathrm{C}$ \\
Removal chamber temperature & $150{ }^{\circ} \mathrm{C}$ \\
Laser power (hatching) & $6,10,14,18,22,25 \mathrm{~W}$ \\
Scan speed (hatching) & $2500 \mathrm{~mm} \mathrm{~s}^{-1}$ \\
Scan Spacing & $0.20 \mathrm{~mm}$ \\
Pre-heat time & $2 \mathrm{hr}$ \\
\hline
\end{tabular}


Table 2 Kissinger data points for PA-12 TGA

\begin{tabular}{|c|c|c|c|}
\hline \multirow{2}{*}{ Polyamide-12 } & \multicolumn{3}{|c|}{ Heating Rate $\left({ }^{\circ} \mathrm{C} / \mathrm{min}\right)$} \\
\cline { 2 - 4 } & 5 & 10 & 20 \\
\hline $\mathrm{T}$ at $1 \%$ weight $\operatorname{loss}\left({ }^{\circ} \mathrm{C}\right)$ & 308 & 325 & 351 \\
\hline $\mathrm{T}-\max \left({ }^{\circ} \mathrm{C}\right)$ & 431 & 438 & 450 \\
\hline
\end{tabular}


Table 3 Physical parameters for determination of degradation energy

\begin{tabular}{|l|l|l|}
\hline$E_{\text {Deg }}$ & & $\mathrm{J} \mathrm{mm}^{-3}$ \\
\hline$T_{\text {DegOnset }}$ & 325 & ${ }^{\circ} \mathrm{C}$ \\
\hline$T_{m}$ & 185 & ${ }^{\circ} \mathrm{C}$ \\
\hline$C_{p}$ & 3155 & $\mathrm{~J} \mathrm{~kg}^{-1} \mathrm{~K}^{-1}$ \\
\hline$E_{a}$ & 279.5 & $\mathrm{~kJ} \mathrm{~mol}^{-1}$ \\
\hline$M_{w}$ & 18800 & $\mathrm{~g} \mathrm{~mol}^{-1}$ \\
\hline$\delta$ & 0.97 & $\mathrm{~g} \mathrm{~cm}^{-1}$ \\
\hline
\end{tabular}


Table 4 Physical Parameters for energy to melt layer

\begin{tabular}{|l|l|l|}
\hline$E_{m}$ & & $\mathrm{~J} \mathrm{~mm}^{-3}$ \\
\hline$T_{b}$ & 172 & ${ }^{\circ} \mathrm{C}$ \\
\hline$T_{m}$ & 185 & ${ }^{\circ} \mathrm{C}$ \\
\hline$C_{p}$ & 3250 & $\mathrm{~J} \mathrm{~kg}^{-1} \mathrm{~K}^{-1}$ \\
\hline$h_{f}$ & 97.2 & W.g \\
\hline$p$ & 0.5 & Dimensionless \\
\hline$\delta_{s}$ & 0.97 & $\mathrm{~g} \mathrm{~cm}^{-1}$ \\
\hline
\end{tabular}


Table 5 Laser Sintering build parameters

\begin{tabular}{|l|l|l|}
\hline $\mathrm{P}$ & & $\mathrm{W}$ \\
\hline $\mathrm{V}_{\mathrm{c}}$ & 1 & Dimensionless \\
\hline $\mathrm{V}_{\mathrm{s}}$ & 0.20 & $\mathrm{~mm}$ \\
\hline $\mathrm{V}_{\mathrm{b}}$ & 2500 & $\mathrm{~mm} \mathrm{~s}^{-1}$ \\
\hline $\mathrm{Z}$ & 0.1 & $\mathrm{~mm}$ \\
\hline
\end{tabular}

\section{Figure Captions}

Figure $1 \quad$ Laser sintering test specimen and build setup side view

Figure 2 Moisture content adjustment for PA-12 powders

Figure 3 PA-12: Modified TGA results at variable heating rates

Figure $4 \quad$ TGA results for $1 \%$ weight loss at various heating rates

Figure 5 Hot Stage microscopy for PA-12

Figure 6 Stable Sintering Region for PA-12 
Figure 7

Figure 8

Figure 9

Figure 10

Figure 11

Figure 12

Figure 13
Typical TGA and derivative weight loss plot with onset temperature and maximum conversion temperature

Kissinger plot for experimental TGA work at variable heating rates using PA-12 Molecular weight distribution for PA-12 using GPC

In-process image of the effect of variable laser power $(6-25 \mathrm{~W})$ on tensile specimens

PA-12 tensile properties data: tensile strength

PA-12 tensile properties data: elongation at break

PA-12 tensile properties data: Young's Modulus 

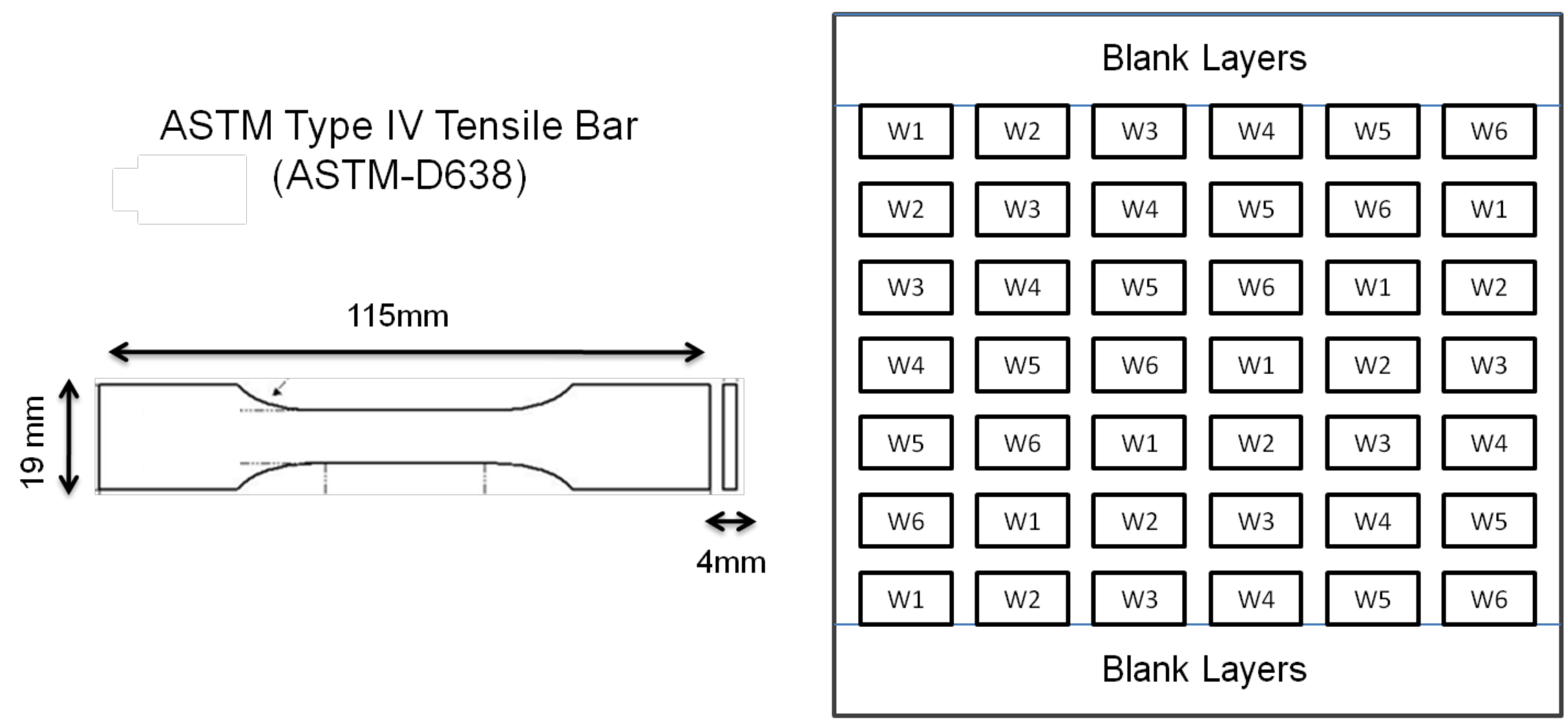

Figure 1: Laser sintering test specimen and build setup side view 


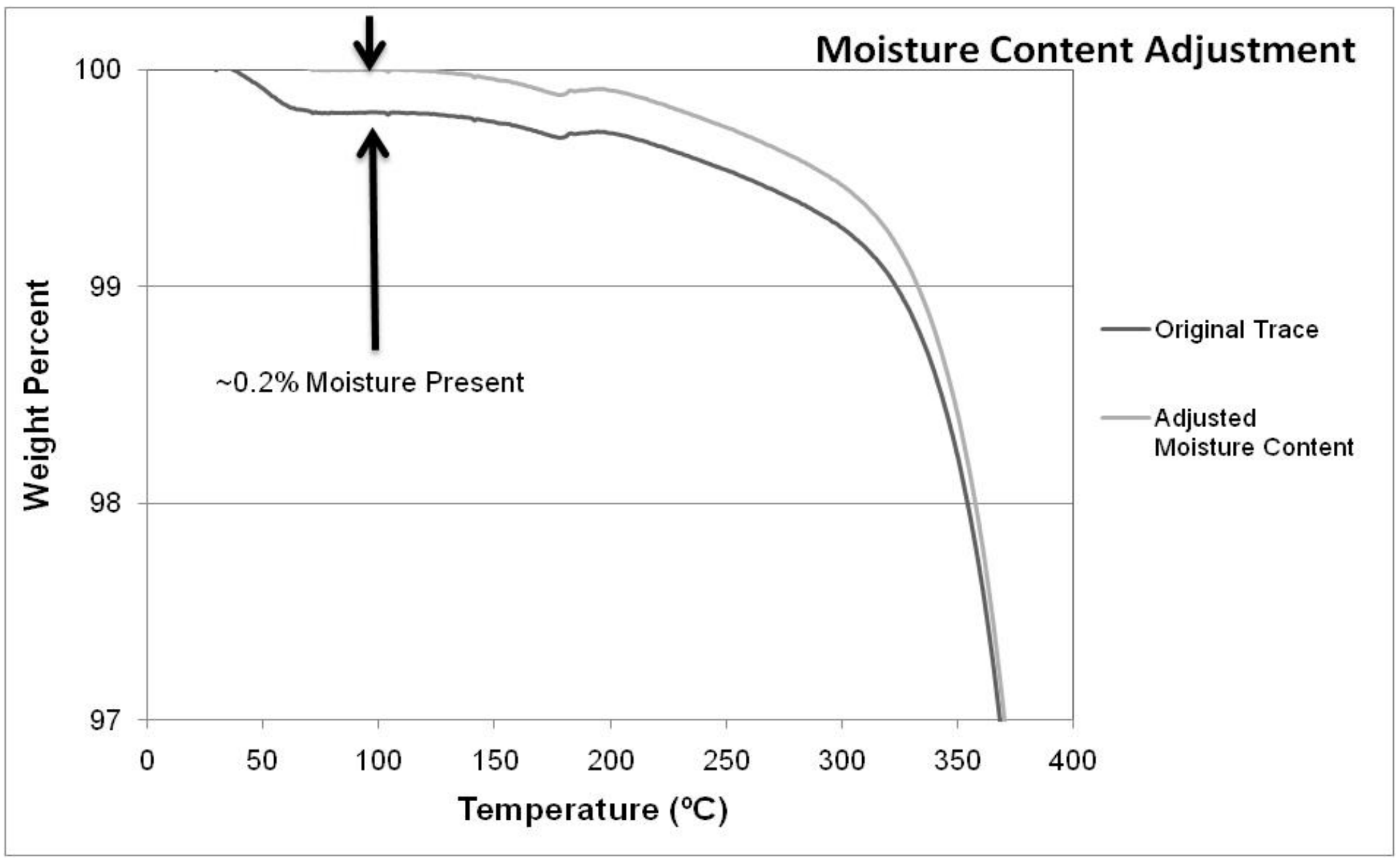

Figure 2: TGA Moisture content adjustment for $\mathrm{PA}-12$ powders 


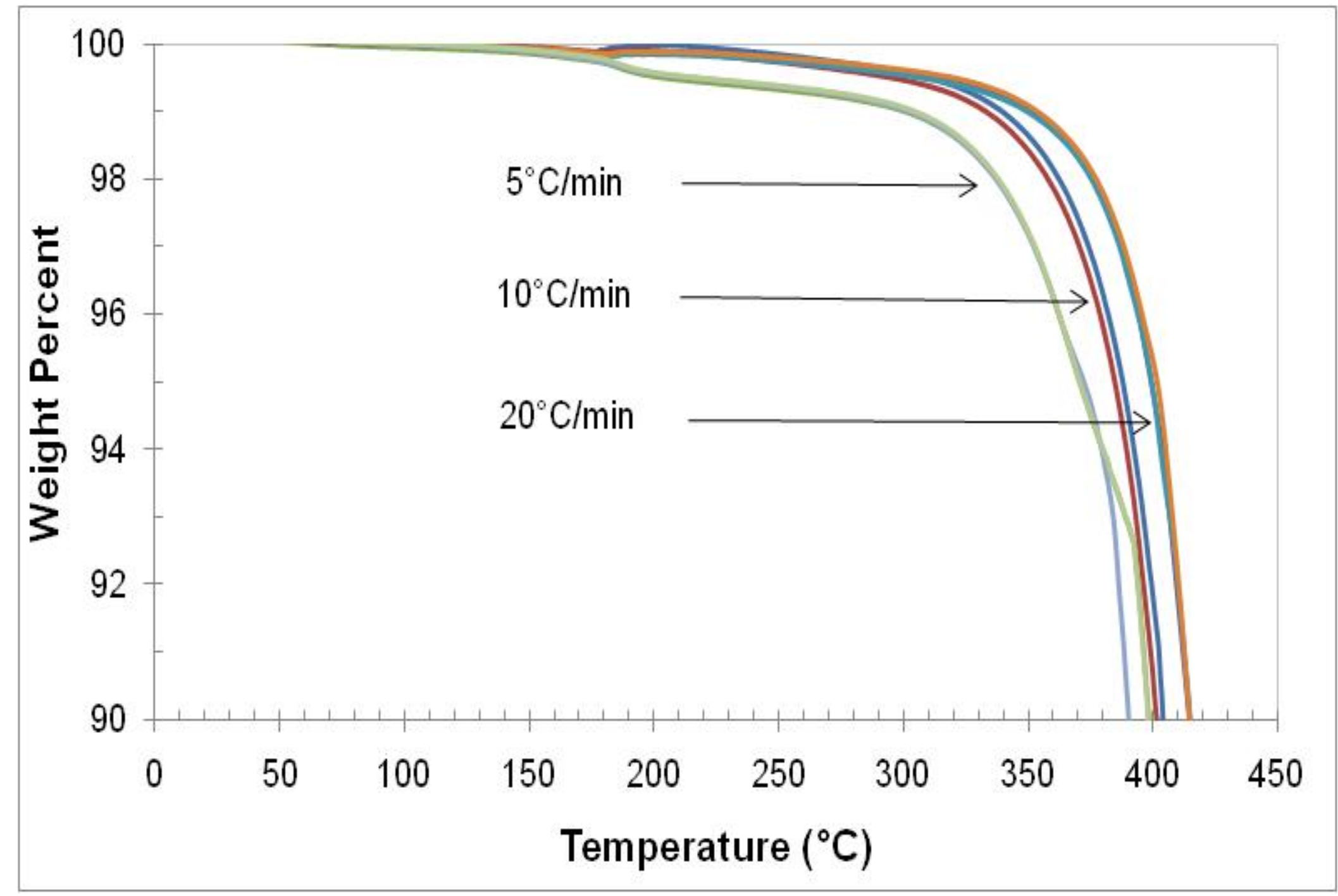

Figure 3: PA12 - modified TGA results at variable heating rates. 


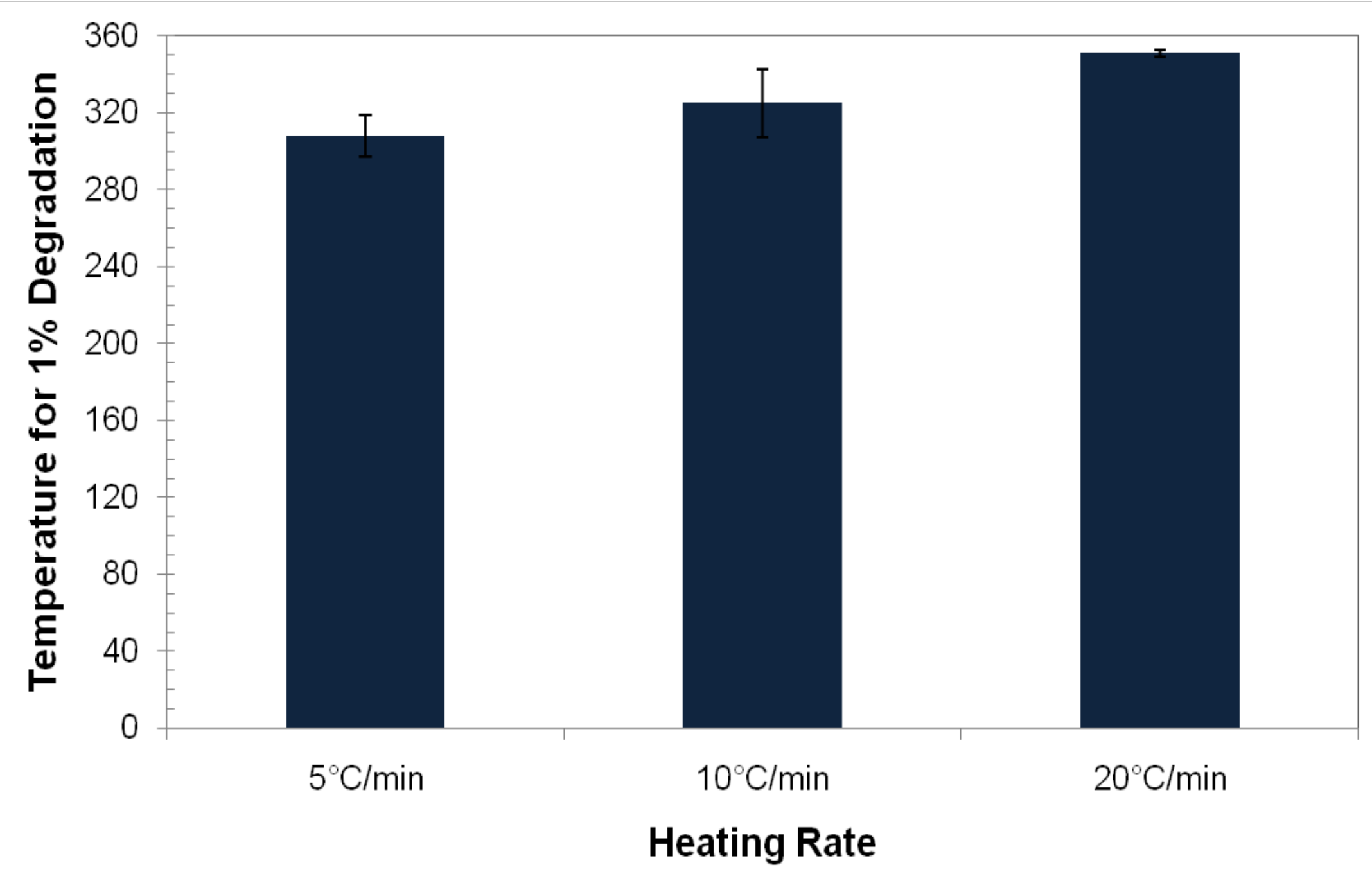

Figure 4: TGA results for $1 \%$ weight loss at various heating rates. 

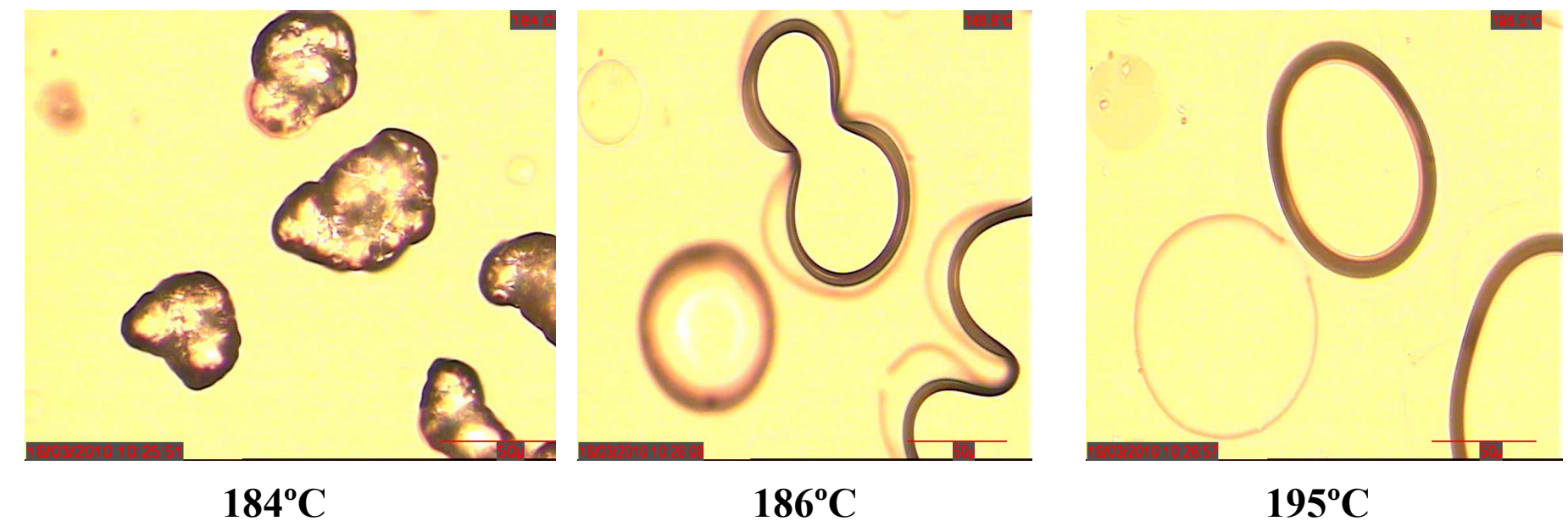

Figure 5: Hot Stage Microscopy for PA-12 


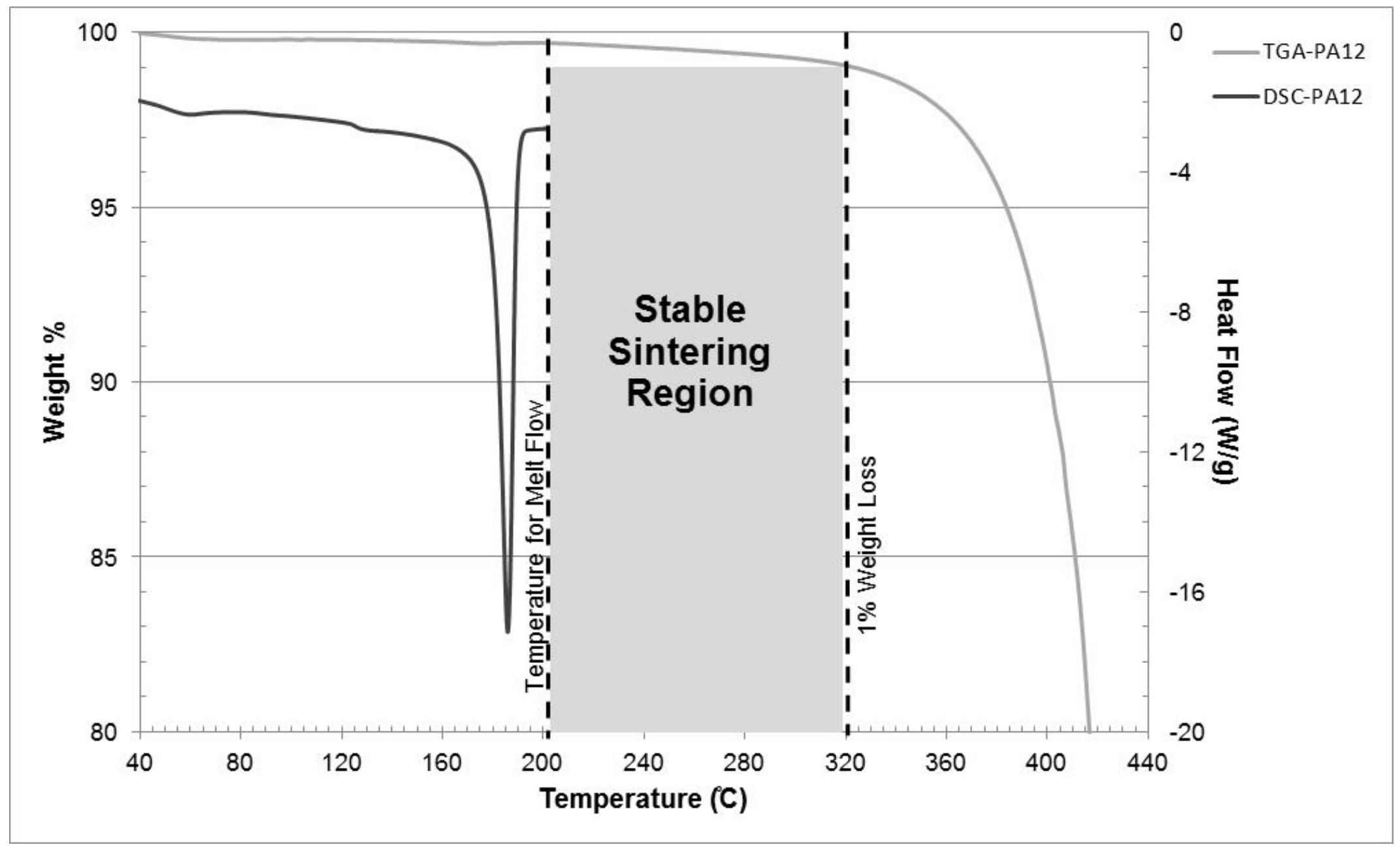

Figure 6: 'Stable Sintering Region' for PA12

Figure 7 Typical TGA and derivative weight loss plot with onset temperature and maximum conversion temperature 


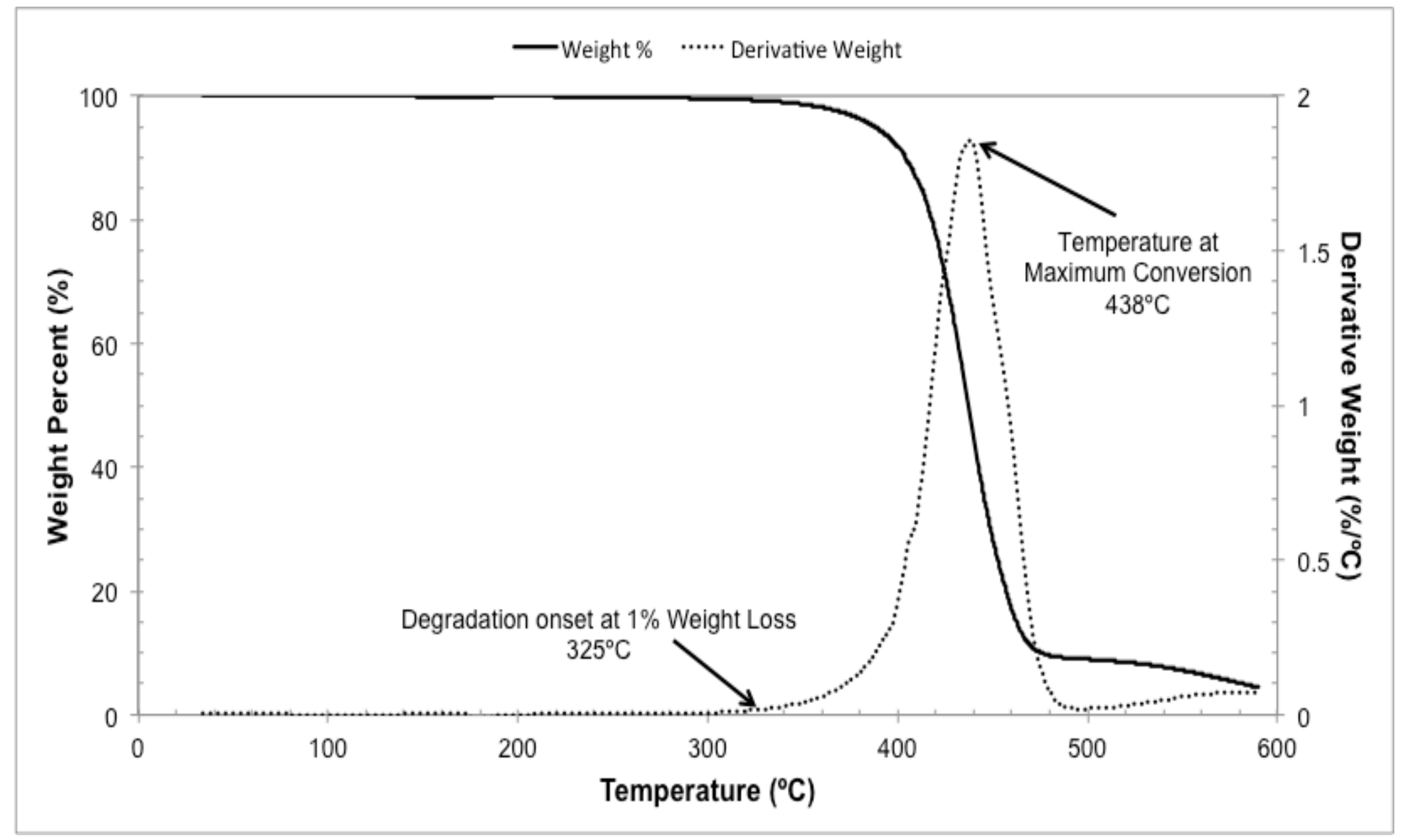

Figure 7 Typical TGA and derivative weight loss plot with onset temperature and maximum conversion temperature 


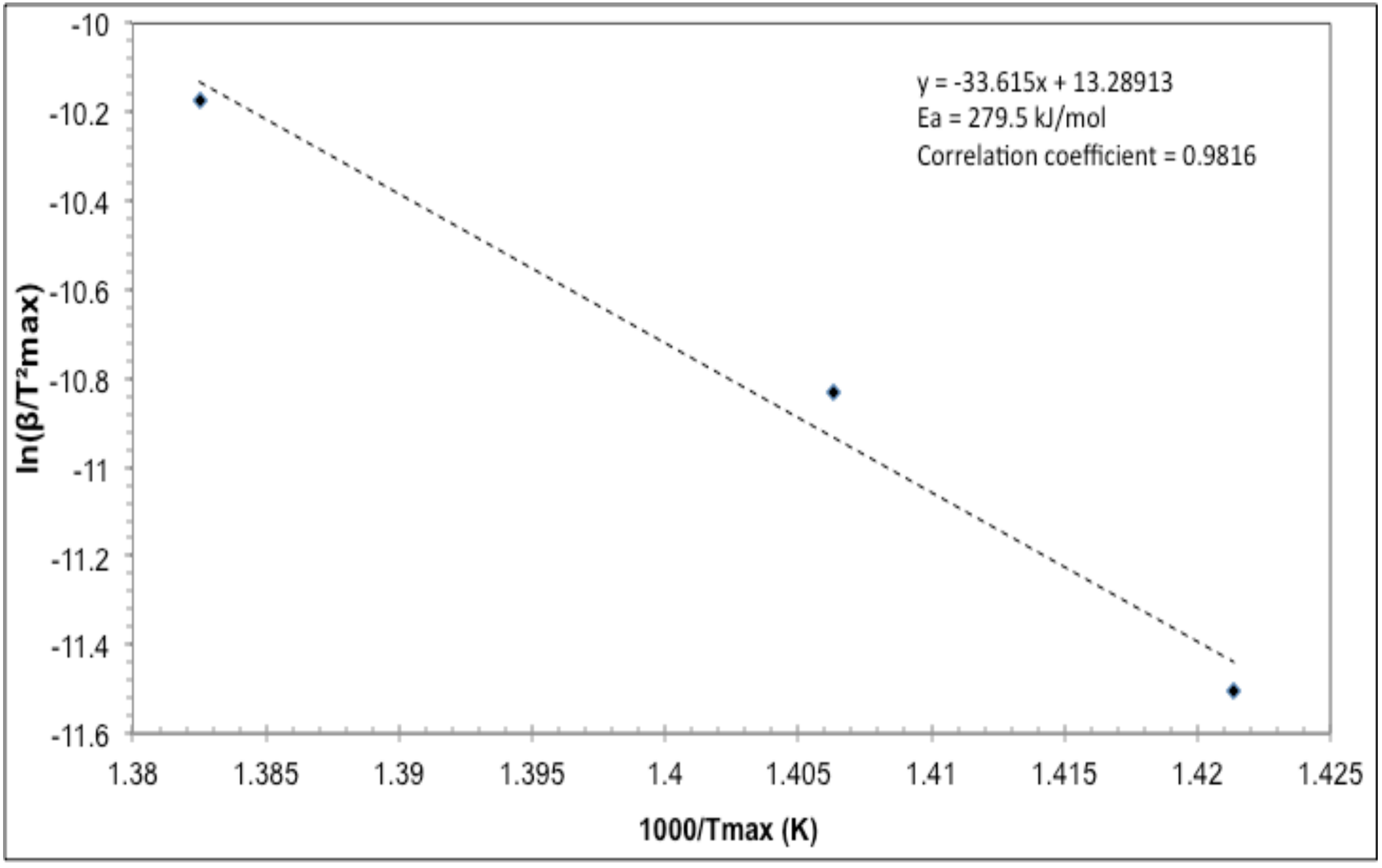

Figure 8 Kissinger plot for experimental TGA work at variable heating rates using PA-12 


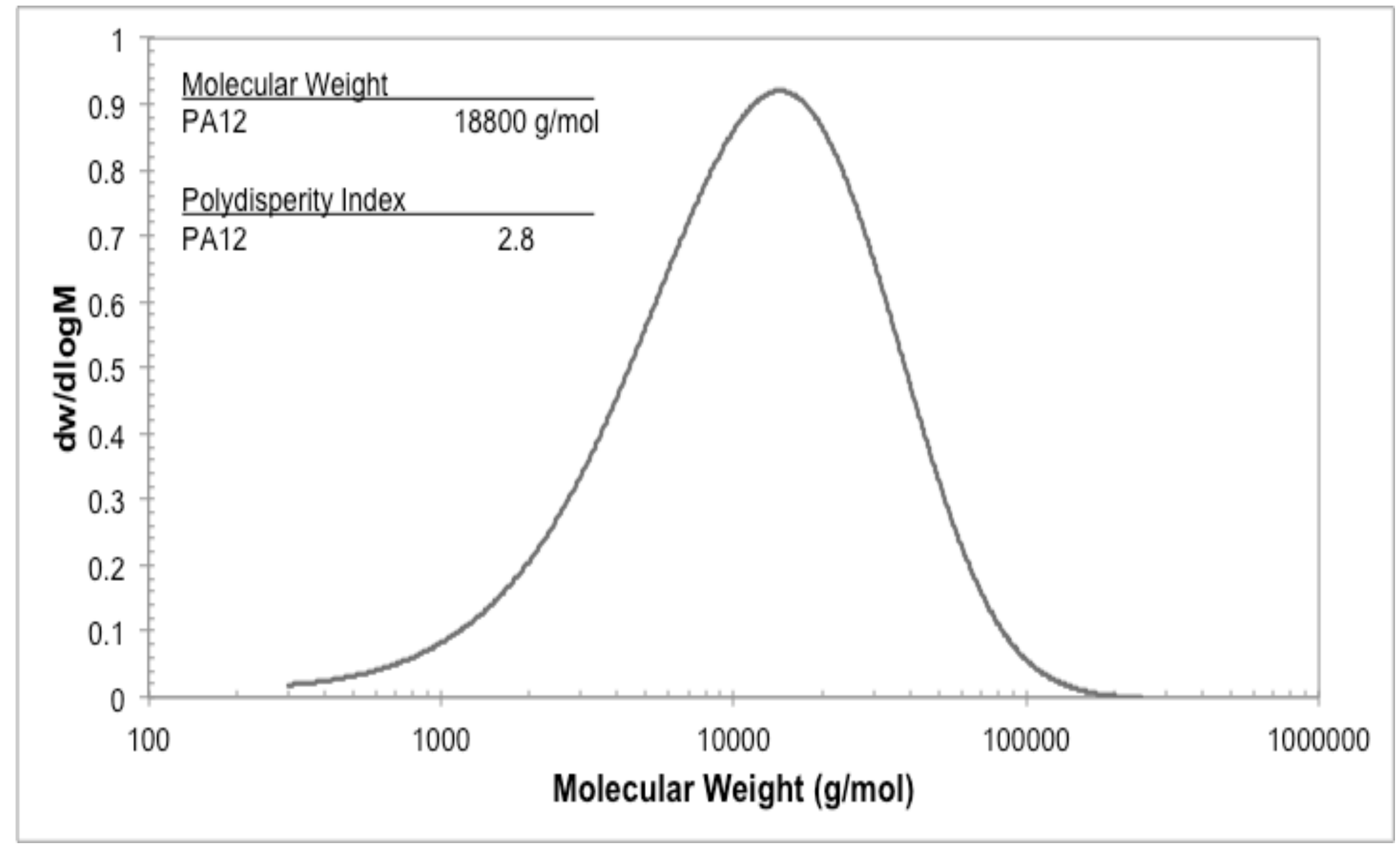

Figure 9 Molecular weight distribution for PA-12 using GPC 


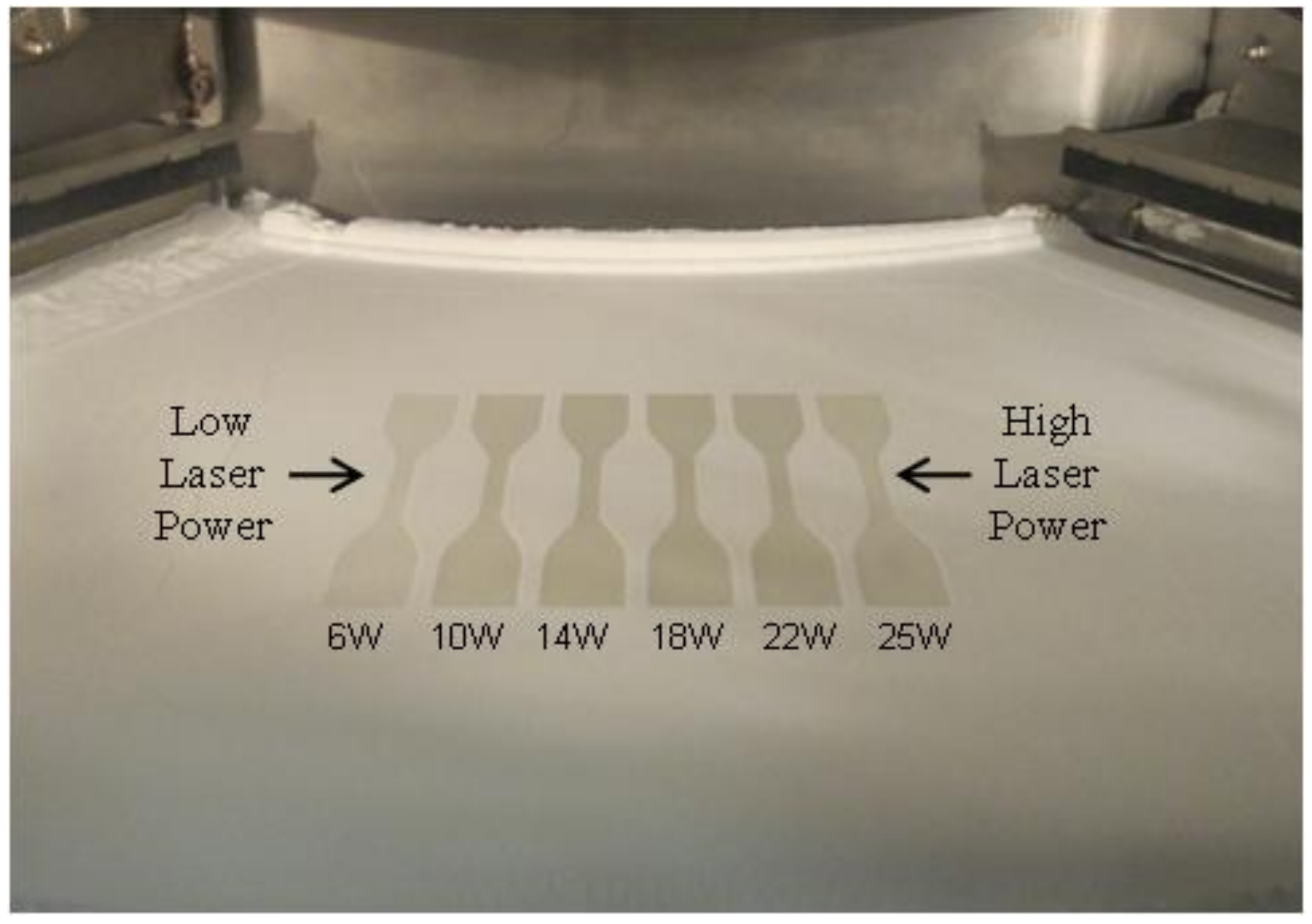

Figure 10 In-process image of the effect of variable laser power (6-25W) on the tensile specimens 


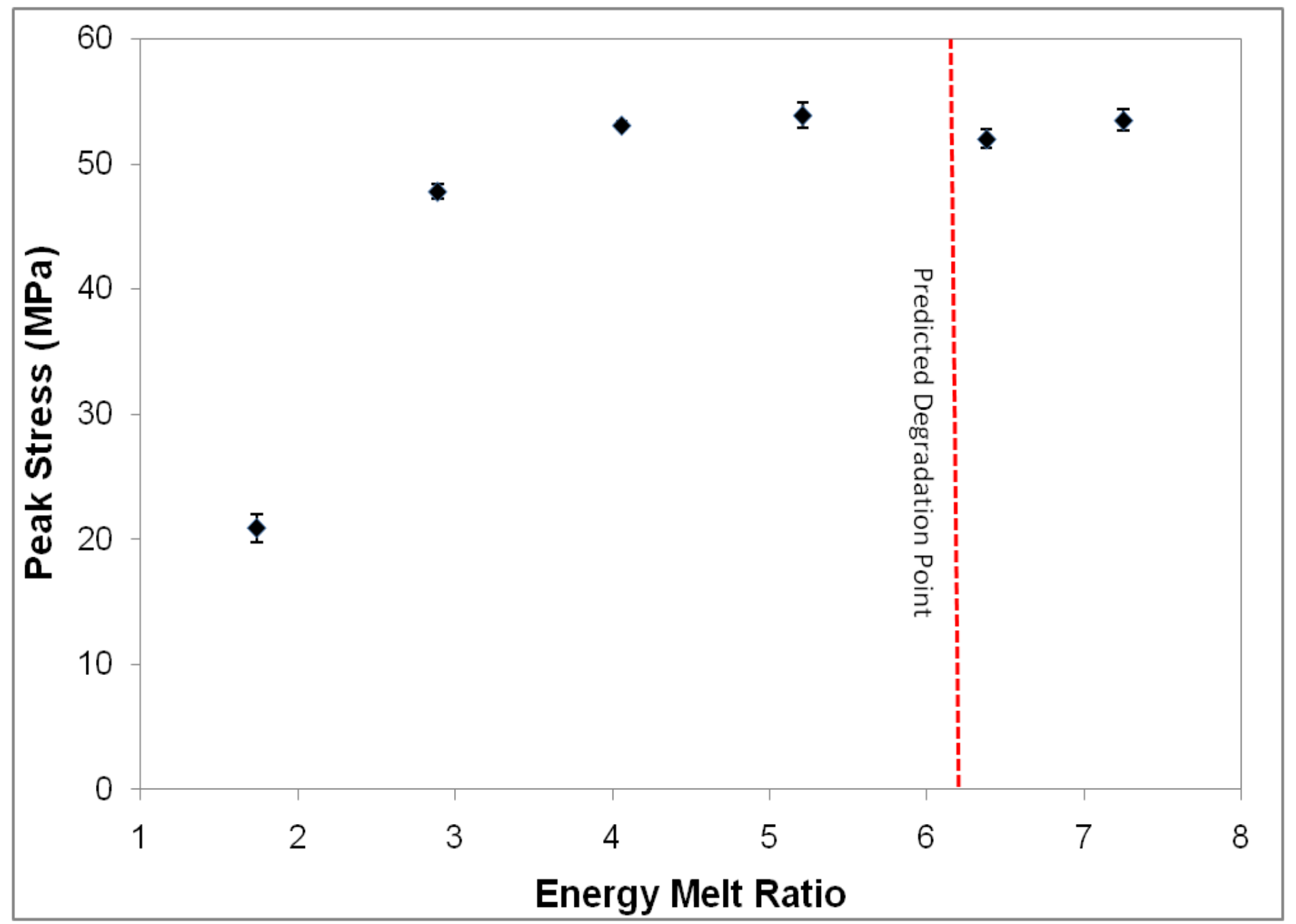

Figure 11 PA-12 Tensile properties data: tensile strength 


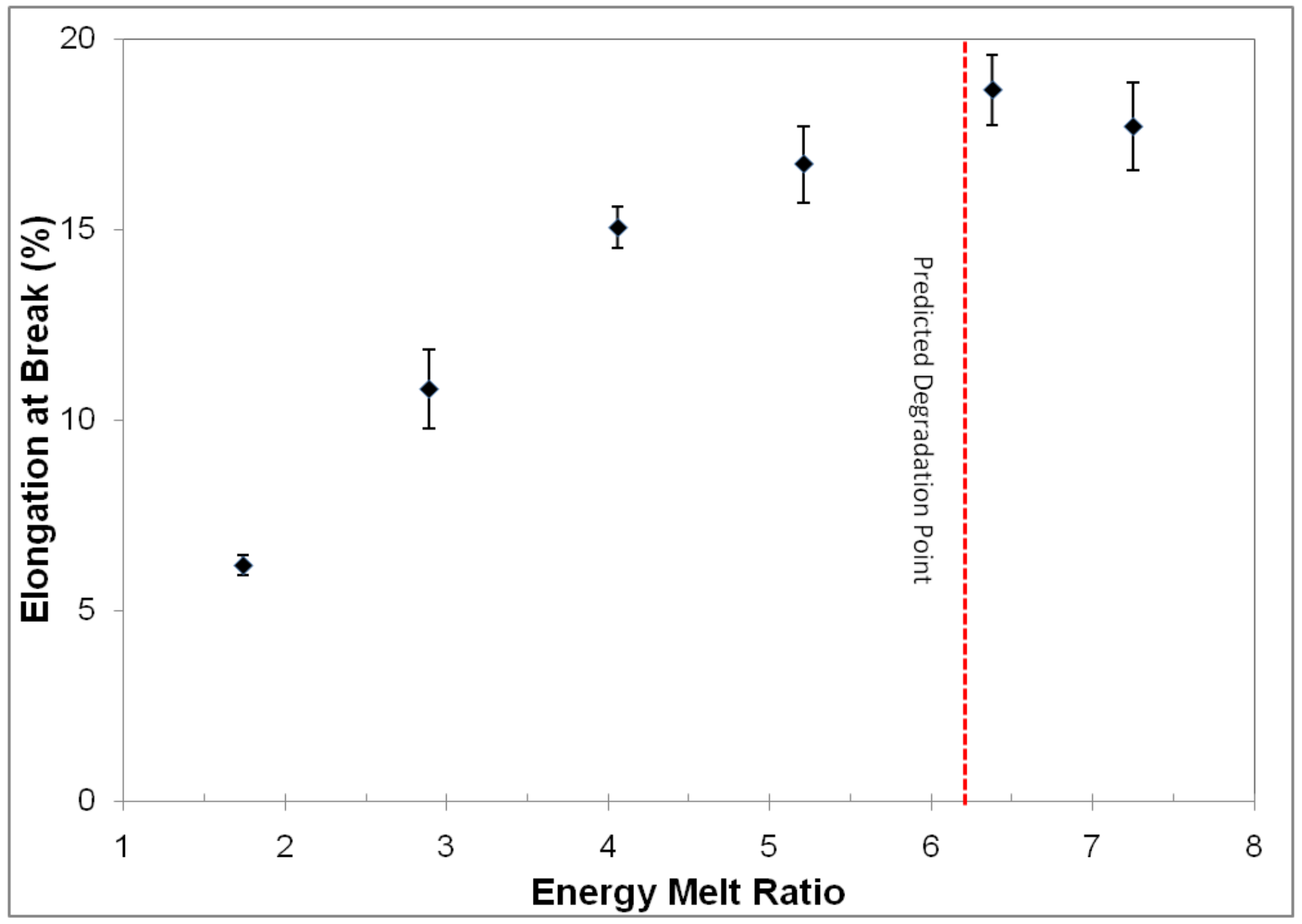

Figure 12 PA-12 Tensile properties data: elongation at break 


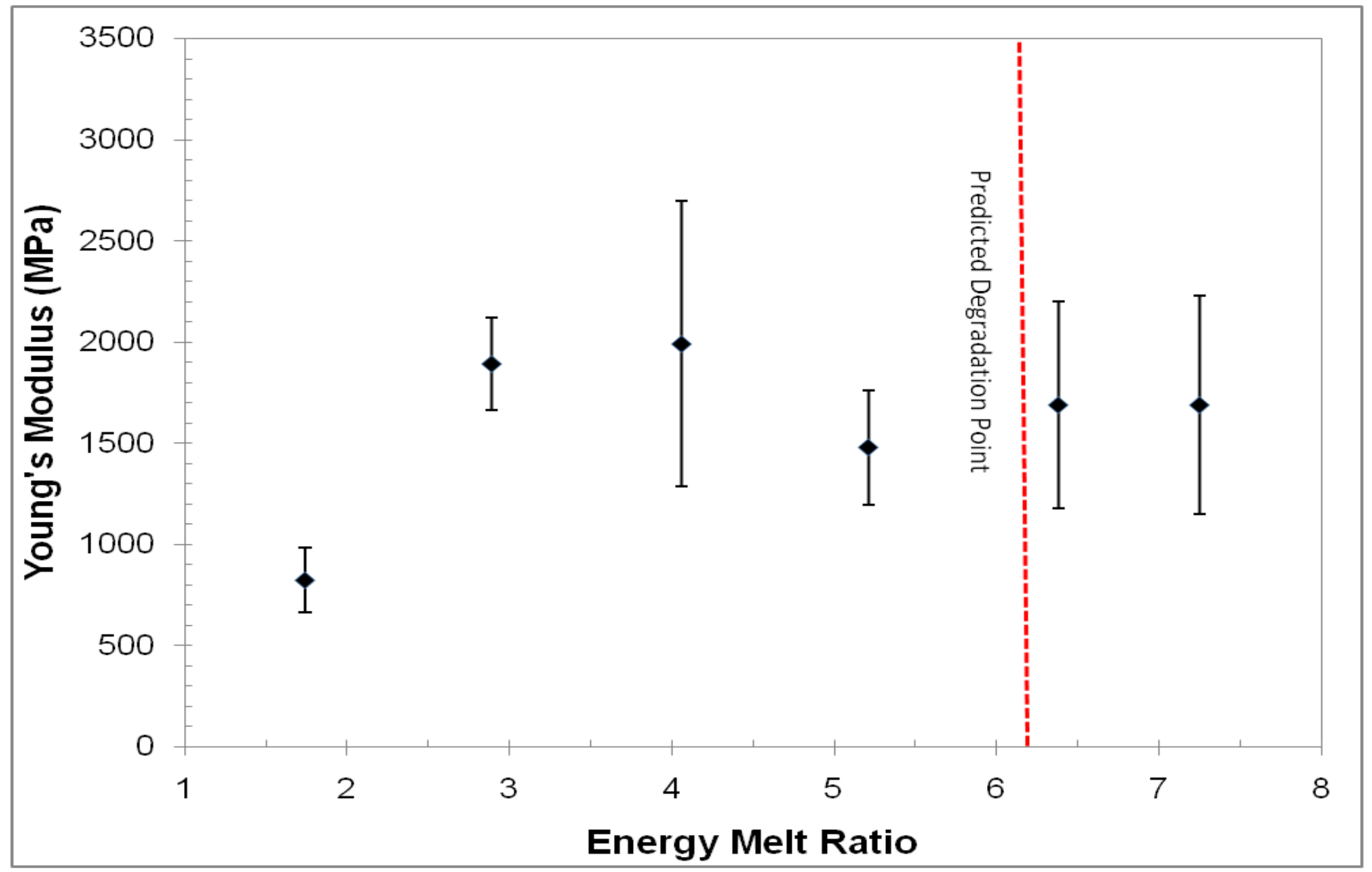

Figure 13 PA-12 Tensile properties data: Young's modulus 